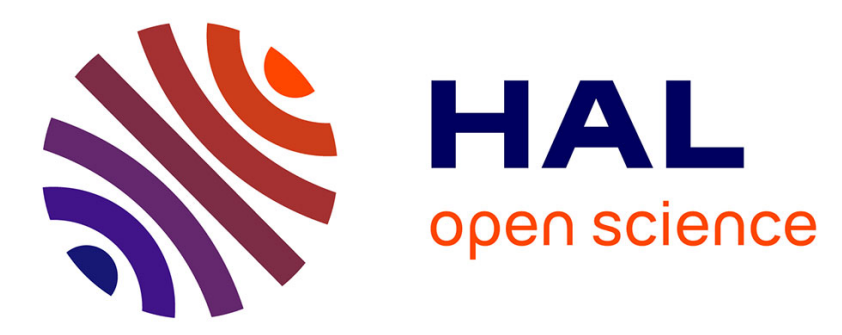

\title{
Enigmatic hook-like structures in Cretaceous ammonites (Scaphitidae)
}

Isabelle Kruta, Jérémie Bardin, Christopher P A Smith, Paul Tafforeau, Neil

H Landman

\section{- To cite this version:}

Isabelle Kruta, Jérémie Bardin, Christopher P A Smith, Paul Tafforeau, Neil H Landman. Enigmatic hook-like structures in Cretaceous ammonites (Scaphitidae). Palaeontology, 2020, 63 (2), pp.301-312. 10.1111/pala.12457 . hal-02962300

\section{HAL Id: hal-02962300 https://hal.sorbonne-universite.fr/hal-02962300}

Submitted on 9 Oct 2020

HAL is a multi-disciplinary open access archive for the deposit and dissemination of scientific research documents, whether they are published or not. The documents may come from teaching and research institutions in France or abroad, or from public or private research centers.
L'archive ouverte pluridisciplinaire HAL, est destinée au dépôt et à la diffusion de documents scientifiques de niveau recherche, publiés ou non, émanant des établissements d'enseignement et de recherche français ou étrangers, des laboratoires publics ou privés. 


\title{
ENIGMATIC HOOK-LIKE STRUCTURES IN CRETACEOUS AMMONITES (SCAPHITIDAE)
}

\author{
ISABELLE KRUTA ${ }^{1,3}$, JÉRÉMIE BARDIN ${ }^{1}$, CHRISTOPHER P. A. SMITH ${ }^{1}$, PAUL $^{2}$ \\ TAFFOREAU ${ }^{2}$, NEIL H. LANDMAN ${ }^{3}$
}

${ }^{1}$ CR2P - Centre de Recherche en Paléontologie - Paris, UMR 7207, Sorbonne UniversitéMNHN-CNRS, 4 place Jussieu, case 104, 75005 Paris, France e-mails: isabelle.kruta@ sorbonneuniversite.fr, jeremie.bardin@sorbonne-universite.fr, christopher.pierre.a.smith@ gmail.com

${ }^{2}$ European Synchrotron Radiation Facility, ESRF, 71 avenue des Martyrs, CS40220, 38043 Grenoble, France; e-mail: paul.tafforeau @ esrf.fr

${ }^{3}$ Division of Paleontology (Invertebrates), American Museum of Natural History, Central Park West at 79th Street, New York, NY 10024, USA; e-mail: landman@ amnh.org

\begin{abstract}
In the last few decades, hook-like structures have been reported in the Mesozoic ammonite family Scaphitidae. Despite their exceptional preservation and debates about their function, no detailed reconstruction has been available until now. For the first time, we describe the composition and details of the morphology of these structures found in the body chambers of six specimens of the Campanian ammonite Rhaeboceras halli (Meek \& Hayden) using high resolution X-ray imaging. The hook-like structures are composed of a thin layer of brushite. The base of the hooks is open on one side forming an internal cavity, now filled with sediment. The tips of the hooks end in one or two cusps or, rarely, exhibit a blunt end. We used geometric morphometrics to capture the morphological disparity of the bicuspidate morphotypes comprising $98 \%$ of the hooks. Principal component analysis revealed chirality among the hooks and a cluster analysis (Gaussian mixture) recognized five main morphologies. Contrary to the previous interpretation of these structures, we conclude that they are not radular teeth. They are much larger and more variable in size and shape than any known ammonite radulae and completely out of proportion with respect to the size of the jaw. The chirality, the hook-like shape, and the absence of a size relationship between the hooks and the body chambers in which
\end{abstract}


they occur, lead us to propose that these hooks could represent elements of the brachial crown related to copulatory behavior. If so, these would be the first reported remnants of brachial crowns in ammonites.

\section{Keywords}

Ammonites, Scaphitidae, exceptional preservation, hooks, morphometrics.

\section{INTRODUCTION}

The number of arms remains unknown for the Ammonoidea (Klug \& Lehmann 2015) and reconstructing the soft part anatomy of the brachial crown relies on phylogenetic bracketing (Witmer, 1995). Knowledge of the internal anatomical features of ammonites is largely limited to the preservation and study of mineralized or sclerotized elements belonging to the buccal apparatus such as the upper and lower jaws and radula (Tanabe et al. 2015). Nevertheless, some features interpreted as buccal elements are still enigmatic due to their unconventional morphology and could possibly belong to other parts of the animal.

This is the case of large cuspidate structures documented by Kennedy et al. (2002) in specimens of Rhaeboceras halli (Meek \& Hayden, 1856), a recoiled member of the Scaphitidae (Ancyloceratina) from the Upper Cretaceous (Campanian) Bearpaw Shale of Montana (Fig.1, Table 1). These structures occur in the body chambers of many macroconch specimens in close association with the lower jaws and were interpreted as radular elements. However, some of the features of these structures are inconsistent with a radular interpretation, as pointed out by Kruta et al. (2013). The structures are extremely large, as much as four times larger than the teeth in modern nautilus. The radula interpretation was rejected by Kruta et al. (2013) who discovered incontrovertible evidence of radulae in three specimens of Rhaeboceras halli. These radulae occur in situ and the size and morphology of the teeth are completely in agreement with radular teeth known from other aptychophoran ammonites (Kruta et al. 2015).

Similar bicuspidate structures were also described by Landman and Waage (1993) in two other species of Scaphitidae from the Upper Cretaceous (Maastrichtian) Fox Hills Formation. The structures occur in the body chambers of Hoploscaphites spedeni (Landman \& Waage, 1993) and H. nicolletii (Morton, 1842). Since then, Landman et al. (2013) documented additional 
structures in association with $H$. gilberti Landman et al., 2013 from the Upper Cretaceous (Campanian) Pierre Shale in South Dakota (Fig. 1, Table 1).

In order to obtain more data to elucidate the function and origin of these bicuspidate structures, we used X-ray based imaging techniques (Synchrotron and CT-scan) to reveal 446 structures embedded in six specimens of Rhaeboceras halli. We documented the morphological variability of these structures to determine if they comprise a single complex apparatus. We present the first detailed reconstruction of the morphology of these structures in several specimens of Rhaeboceras halli.

\section{MATERIAL AND METHODS}

\section{Material}

The specimens of Rhaeboceras halli studied are from the upper Campanian Baculites jenseni Zone of the Bearpaw Shale, Garfield County, Montana, USA (Fig. 1, Table 1). Over 30 specimens containing hook-like structures are deposited at the American Museum of Natural History (AMNH). A total of 12 specimens were CT-scanned in order to investigate the quality of preservation. All of the specimens consist of fragments of the body chambers of macroconchs, with only pieces of the outer shell wall preserved. The shell wall retains the original nacreous microstructure, indicating excellent preservation. Moreover, three of the specimens contain the lower jaw in the anterior end of the body chamber and one specimen (AMNH 51334) contains both lower and upper jaws and the radula in the posterior part of the body chamber (Kruta et al., 2013). Six of these specimens (AMNH 64405, 66448, 66350, 66351, 66433 and 66434,) were very well preserved and were selected for more detailed investigations of all of the hooks inside the body chambers, using $\mu \mathrm{CT}$-scanning and propagation phase-contrast X-ray synchrotron Microtomography (PPC-SR- $\mu \mathrm{CT}$ ). In the majority of specimens, the structures occur on the outer surface of the body chamber against the flanks or venter (Fig. 2). Because of the presence of cusps, we refer to these structures as hooks. We use this as a general term, in full recognition of the fact that these structures do not curve backward as in coleoid hooks.

\section{Data acquisition}


Data acquisition was performed using $\mu \mathrm{CT}$-scanning at the AMNH and PPC-SR- $\mu$ CT scanning at the Synchrotron ESRF (proposal es-859). Specimens AMNH 64405, 66351, 66433, 66434, were scanned at the AMNH with a GE PHOENIX v|tome|x s 240, while AMNH 66350 and 66448 were scanned at ESRF on ID19. Scan parameters for this study are available in the Dryad Digital Repository (Kruta et al. 2019).

3-D segmentation was performed using VG Studio MAX 3.0 (Volume Graphics, Heidelberg, Germany). 3-D reconstruction of the structures was performed manually or using threshold tools. In X-ray examination, the low-density material comprising the hooks appears darker than the surrounding mineral matrix, facilitating reconstruction. When the material composing the hooks was missing due to taphonomic factors, the void corresponding to the hook was used for reconstruction. Many of the hooks are located on the exposed surface of the body chamber with the black layer eroded away, making 3-D reconstruction impossible in those areas. As a result, only $52 \%$ of the hooks are preserved as complete structures, and can be used for quantitative analysis.

\section{Composition}

The composition of the hooks (specimen AMNH 66349) was determined using EDX and micro X-ray diffractometry (Texray Laboratory Service, Brucker D5000 X-ray diffractometer).

\section{Morphometric analysis}

In order to analyze the overall morphology of the hooks, landmarks were positioned on the bestpreserved structures in VG Studio Max 3.0 for a total of 183 bicuspidate hooks. The base of the hooks is convex and forms a circular to ovoid opening on one side. Therefore, nine landmarks were used to describe the morphology of the hooks, four of which were located around the opening (Fig. 3).

The coordinates of the landmarks were exported and analyzed using $\mathrm{R}$ software (R Core Team 2016). A procrustes transformation was performed to remove the effects of size, position, and rotation. Exploratory analyses such as PCA were used to gain insights into the structure of the data in multivariate morphometric space and clustering was performed using a Gaussian mixture model (Everitt \& Dunn, 2001) with functions from the R package mclust (Fraley et al. 2012). 


\section{RESULTS}

\section{Composition and general description}

In all the studied specimens, the hooks are composed of a layer of black material $0.15 \mathrm{~mm}$ thick (Fig. 4.). EDX and XRD analyses performed on this black layer (Fig. 4) indicate two different phases (Kruta et al. 2019). The main crystalline phase identified is brushite $\left(\mathrm{Ca}\left(\mathrm{PO}_{3} \mathrm{OH}\right) \mathrm{x}\right.$ $\mathrm{H}_{2} \mathrm{O}$ ). Two amorphous regions were also identified, one of them characterized by longer bonds typical of organic compounds. The shape of the hooks forms a cavity subsequently filled in with the matrix sediment. The main crystalline phase identified for the matrix in XRD is calcite.

The number of hooks varies among the specimens from 40 in AMNH 66351 to 171 in AMNH 66350. These differences could be related either to differences in preservation (different size fragments of body chamber, parts of the body chamber exposed or eroded) or to variation in the original number of hooks. The specimen with the largest number of hooks in the body chamber (AMNH 66350) is 1) among the largest specimens based on estimates of body chamber size and 2) the specimen with the smallest number of hooks exposed in the body chamber.

The structures are generally bicuspidate although some are unicuspidate, tricuspidate, and one is rounded (Fig. 5). The morphological variation of the hooks is described with the opening facing us and the cusps pointing to the top (Fig. 3A). This orientation is used to define the left and right sides of the hooks.

The hook with a rounded tip (Fig. 5G) was identified in AMNH 66350. This hook is almost $8 \mathrm{~mm}$ long and the rounded tip is flattened. In the same specimen, three unicuspidate hooks less than $1 \mathrm{~mm}$ in length were also found (Fig. 5K). Tricuspidate hooks (Fig. 5O) were found in three specimens (AMNH 64405, 66448, and 66350) for a total of six hooks. Their size approaches $1 \mathrm{~mm}$ and the middle cusp is slightly longer compared to the two others, similar to the dimensions of a rachidian tooth in a radula. Approximately $98 \%$ of the remaining hooks recorded are bicuspidate. Their morphology varies from elongate (e.g., Fig. 5C-D) to short (e.g., Fig. 5A) with variation of cusp length and opening size. During the segmentation, several types

of hooks were identified, based on their overall morphology and size (Fig. 5). In order to have better insights into the morphological disparity among these bicuspidate hooks, quantitative 
analyses were performed on the best-preserved specimens through the use of landmarks. One group of bicuspidate hooks (Fig. 5F) with length less than $1 \mathrm{~mm}$ was too small for precise landmark placement on the 3D program. This small morphotype was encountered in almost all specimens (except AMNH 64405), for a total of 43 hooks. The cusps are almost sub-equal in sizes with the tips of the cusps pointing slightly inward (Fig. 5F).

\section{Bicuspidate hooks description}

PCA analyses. Most hook shape variation is accounted for by a relatively small number of axes (Fig. 6). The three first PC-axes represent $88.9 \%$ of the variance. The main morphological trend on PC1 (49.8\% of the variance) is associated with variation from a long slender hook with the right cusp longer than the left cusp, to a larger form with the left cusp longer than the right. PC2 (31.7\% of the variance) reflects the variation in the size and position of the opening. The positive part of the axis reflects long and slender hooks with the opening in the lower part, and the negative part of the axis reflects shorter hooks with a larger opening. Variation on PC3 (7.3\% of the variance) represents a trend where the cusps are either short with an acute angle between them or long with an obtuse angle between them.

Gaussian mixture analyses. Gaussian mixture analyses (Everitt \& Dunn, 2001) were performed focusing on the three first PC-axes. A 5-group solution (Fig. 7) emerged with the highest BIC (Bayesian Information Criterion). Among the 5 groups, two pairs (G1-G5 and G2-G4) are mirror images (Fig. 7). The groups G1 and G5 (Fig. 7) represent a slender morphology with a small opening. The right or left cusp predominates. Groups G2 and G4 (on the right and left sides of the graph) represent wider hooks with larger openings. The last group (G3) reflects hooks with nearly symmetric cusps.

Size of the hooks. The distance between landmarks 3 and 5, corresponding to the maximum linear length of the hooks ranges from $1.64 \mathrm{~mm}$ to $25.41 \mathrm{~mm}$. The size variation of the hooks was studied by plotting the centroid size for each morphogroup per specimen (Fig. 8). The overall distribution is similar for all specimens (Fig. 8A) and will be described only for AMNH 66350 (the most complete specimen). The chiral groups G1 and G5 represent the most common 
bicuspidate structures. The box plot for these structures is comparatively tall with similar median values indicating a similar range of sizes. Within these two groups, the size of the largest hook is two to four times the size of the smallest hook. The size range of the chiral groups (G2) and (G4) only partially overlaps. Although a higher number of hooks are preserved in G4 group, the boxplot is relatively shorter with a median lower than in the red group. The G3 group exhibits the lowest values of centroid sizes in AMNH 66350 and all the other specimens where it is recorded.

Following this first analysis indicating chiral structures, we decided to transform (flip) all the hooks from those with left cusps dominant into hooks with right cusps dominant.

PCA on flipped hooks. The five first PC-axes summarize $89.1 \%$ of the variance. The main morphological trends are associated with variation in the angle between the plane of the opening and the plane of the cusps. PC1 (60.5\% of the variance) is associated with variation from a long slender hook with a small opening, to a larger, almost equally sized cuspidate hook, with the opening extremely large. PC2 (18.8\% of the variance) reflects the variation between hooks with long dominant cusps forming an open angle with the second cusp, a large opening, and a very narrow angle between the opening and the tips of the cusps (the hook is flat) to hooks with cusps almost equal in size, an opening in the lower part of the hook, and a large angle between the opening and the tips of the cusps. Variation on PC3 (4.2\%) represents a trend where the cusps are either short with an acute angle between them or long with an obtuse angle.

Gaussian mixture analyses on flipped hooks. The analysis was performed on the four first PCaxes. A 5-group solution (Fig. 9) emerged with the highest BIC (Bayesian Information Criterion). The groups G2F and G3F are similar with a small opening in the lower part and a slender morphology. Both G1F and G5F hooks present large openings and cusps. In the last group G4F, the cusps are almost equal in size with a relatively large opening. Although groups were identified, the data distribution indicates a continuum in shape.

Size of the hooks vs estimated size of the ammonite. In order to visualize the relationship between the size of the hooks and the ammonites in which they occur, we plotted a boxplot of GPA 
centroid size of each morphogroup per specimen sorted by their whorl height at the base of the body chamber (Fig. 10). Ammonite size estimates expressed by the whorl height at the base of the body chamber must be regarded with caution as the specimens are incomplete and sometimes partially crushed. For AMNH 66334, AMNH 66350, AMNH 66433, as only parts of the body chamber are preserved, the estimates are based on more complete specimen of comparable size (e. g. AMNH 95898). From figure 10, no relationship can be identified and this is confirmed by the Spearman correlation test $($ rho $=-0.075, \mathrm{p}$ value $=0.31)$.

Length of hooks versus length of lower jaw. For comparative purposes, ratios were calculated between the length of the lower jaws and the length of the radular teeth for other ammonites in which both structures were preserved in situ and were measurable: Baculites (Ancyloceratina, Aptychophora) (AMNH 55901) and Cravenoceras (Goniatitina) (AMNH 66407). In Baculites (AMNH 55901), the longest radular element (the marginal tooth) is $2 \mathrm{~mm}$ tall and is $5 \%$ of the maximum length of the wing of the lower jaw. In Cravenoceras (AMNH 66407), the length of the marginal tooth $(0.8 \mathrm{~mm})$ is $6 \%$ of the maximum length of the wing of the lower jaw. In contrast, the hooks in $R$. halli are a magnitude of size larger. In AMNH 66433 with the lower jaw (aptychus) in situ the largest hook element $(12.6 \mathrm{~mm}$ long) is $30 \%$ of the maximum wing length of the lower jaw $(43.9 \mathrm{~mm})$.

\section{DISCUSSION}

With the exception of a few mono, tri, and non-cuspidate hooks ( $2 \%$ of the hooks reconstructed), the vast majority of hooks exhibit two cusps. Results from quantitative analyses indicate that fewer morphotypes among the bicuspidate hooks exist than it first appeared during 3D segmentation. Two pairs of groups with the same morphologies but with either the right or left cusp dominant were identified as chirals; one less abundant group contains hooks almost subequal in size. Besides chirality, shape variation includes slender or more robust morphologies, changes in opening size, and variation of the angle between the two cusps. Although discrete groups were identified, a continuum in shape was actually observed and might indicate the presence of intermediate forms in better-preserved specimens, probably linked to morphological 
gradients along structures. Important size variation occurs within groups (sizes double or triple) and between groups with some elements $<1 \mathrm{~mm}$ and others $>20 \mathrm{~mm}$.

The chirality of the hooks is reminiscent of radulae. Rows of teeth on a radular ribbon comprise lateral and marginal teeth symmetrically arranged around the rachidian central tooth, which is often tricuspidate (Kruta et al. 2015). The small tricuspidate morphogroup (1 mm long) is consistent in shape and size with the rachidian tooth of a radula. The recovery of this central tooth of the radular ribbon was missing in the description of Kruta et al. (2013). However, aside from this single structure, all of the other elements that we describe are inconsistent with the shape and size of radular teeth. Indeed, size variation itself is inconsistent with what is observed in radulae. Once secreted by the odontoblasts in the radular sac (Messenger \& Young 1999), the radular teeth do not continue to grow. Therefore, within the same morphotype, the size is homogeneous contrary to what is observed in the hooks (Fig. 5). Moreover, no combination of small $(<1 \mathrm{~mm})$ and large $(>10 \mathrm{~mm})$ elements appears on any radula and the ratio between the size of the hooks and the size of the body chamber is inconsistent to what is known from other ammonite radulae. In addition, the radular teeth lack openings because the teeth are solid chitinous elements. Therefore, the hook-like structures in $R$. halli described herein cannot be interpreted as radular elements as was suggested by Kennedy et al. (2002).

In extant cephalopods, palatine teeth are also present on palps located on either side of the radula in the buccal cavity (e.g., Figs 33-35 O' Shea et al. 2007, Boldstad 2008). These teeth are not homogeneous in size, bear one narrow cusp, and are irregularly embedded on the palps. Neither their size $(\approx 2 \mathrm{~mm})$, nor their shape is similar to what we describe in Rhaeboceras. Based on the number and size of the hook like structures in Rhaeboceras, if they were palatine teeth, they would hardly fit on the palps in the buccal cavity. Therefore, we discard the palatine teeth interpretation as a possible explanation for the hook like structures in Rhaeboceras.

The lack of a relationship between the size of the ammonites (approximated by the size of the body chamber) and the size of the hooks (Fig. 10) could indicate that these structures do not belong to these individuals. The superficial resemblance of the hooks to claws (chelipeds) or crustacean appendages evokes a crustacean origin. Examples of inquilinism of ammonite shell by crustaceans are known in the literature (e.g. Fraye \& Jaeger 1995, Landman et al. 2014). Nonetheless, in such cases, several parts of the crustaceans are preserved including parts of the telson, abdomen and feet. In Rhaeboceras no such structures are preserved. The anatomical 
features of the hooks as well as the high number of elements of this single type of structure (171 hooks in AMNH 66350) also rule out this hypothesis.

The fact that these structures are only found in Rhaeboceras halli and no other co-occurring ammonites (e.g., Baculites) strongly suggests they are related to this species and do not represent random infilling of the body chamber. Moreover, the preservation of the jaws in situ in AMNH 66433 indicates, at least for this specimen, that other ammonite structures are preserved as well. Our hypothesis is also supported by the fact that similar structures are present in the same family Scaphitidae in Hoploscaphites spedeni, H. nicolletii, and H. nebrascensis from the Maastrichtian of the U.S. Western Interior, and are closely associated with H. nodosus, H. brevis, and $H$. gilberti from the Campanian of the same basin.

A possible explanation could be that the hooks are structures related to mating, such as hectocotyli (modifications of the arm for reproduction in males). This would explain the lack of a relationship between the size of the ammonites and the size of the hooks. The hooks would have belonged to the males and would have been inserted into the pallial cavity of the females during mating. Modification of the arm suckers -either through enlargement or reduction- together with enlargement of the trabeculae in a variety of combinations is known in several Ommastraphida (Roeleveld, 1988). Although the hook like structures in Rhaeboceras are very different, the distribution of these structures vaguely resemble those in Notodarus, with larger modified elements on the base and smaller modified elements on the distal portion of the arm (Dunning \& Fork, 1998). Because the distribution of the hook like structures in Rhaeboceras have been modified due to taphonomic processes, the original distribution of these structures is difficult to determine. Therefore, the hectocotylus hypothesis is still speculative, although the organic origin

of the material comprising the hooks is consistent with an armature hypothesis. This hypothesis will be explored in further research aiming to study the relative position of the hooks in the body chamber in order to reconstruct the position of the morphogroups along a possible arm.

\section{CONCLUSION}

This first quantitative analysis of the exceptionally preserved hook-like structures found in Rhaeboceras halli allows us to identify the presence of chirality and explore the shape variation. The structures seem to present a plastic morphology dominated by forms with two 
cusps. Shape description could be improved by using finer morphological descriptors such as sliding landmarks or Fourier analysis to capture curvatures of the hooks. Nonetheless, the data already gathered invalidates the interpretation that they are radular elements (contra Kennedy et $a l .$, 2002). Only further analysis will allow a better idea of the organization of the structures with respect to each other. So far, the most plausible hypothesis is that these structures are related to mating in the Scaphitidae. If this were the case, these structures would be the first fossil remains of brachial crown elements in Ammonoidea and would therefore constitute a milestone in our comprehension of the paleobiology of this extinct group.

Acknowledgments. We thank ESRF for proposal acceptance es-859. We also thank Alexandre Lethiers (CR2P) for helping with figures as well as Stephen Thurston (AMNH). We also thank the reviewers C. Klug and anonymous for improving the manuscript.

\section{DATA ARCHIVING STATEMENT}

Data for this study are available in the Dryad Digital Repository: https: https://doi.org/10.5061/dryad.1bg1c1f.

\section{REFERENCES}

BOLSTAD K. S. 2008. Systematics of the Onychoteuthidae Gray, 1847 (Cephalopoda: Oegopsida). Dissertation (PhD), Auckland University of Technology, Auckland, New Zealand. 264 pp.

COBBAN, W. A, WALASZCZYK, I., OBRADOVICH J. D. and McKINNEY K. C. 2006. A USGS zonal table for the Upper Cretaceous Middle Cenomanian-Maastrichtian of the Western Interior of the United States based on ammonites, inoceramids and radiometric ages. U.S. Geological Survey Open-File Report, 1250, 1-46.

DUNNING, M. C. and E. C. FÖRCH. 1998. A review of the systematics, istribution, and biology of arrow squids of the genus Nototodarus Pfefer, 1912 (Cephalopoda: Ommastrephidae). Smithsonian Contributions to Zoology, 586, 393-404.

EVERITT, B. and DUNN, G. 2001. Applied multivariate data analysis. London: Arnold, 316 pp. 
FRAAYE, R. and JÄGER, M. 1995. Decapods in ammonite shells: examples of inquilinism from the Jurassic of England and Germany. Palaeontology, 38, 63-75.

FRALEY, C., RAFTERY, A. E., MURPHY, T. B. and SCRUCCA, L. 2012. Mclust Version 4 for R: Normal Mixture Modeling for Model-Based Clustering, Classification, and Density Estimation. Technical Report No. 597, Department of Statistics, University of Washington.

KENNEDY, W. J., LANDMAN, N. H., COBBAN, W. A. and LARSON N. L. 2002. Jaws and radulae in Rhaeboceras, a Late Cretaceous ammonite. 394-399. In Summesberger, H., Histon, K. and Daurer A. (eds). Abhandlungen Der Geologischen Bundesanstalt, Band 57. Wien. 569 pp.

KLUG, C. and LEHMANN, J. 2015. Soft part anatomy of ammonoids: reconstructing the animal based on exceptionally preserved specimens and actualistic comparisons. 507-529. In Klug et al. (eds). Ammonoid Paleobiology: from anatomy to ecology. Topics in Geobiology, 44, Springer. $934 \mathrm{pp}$.

KRUTA, I., BARDIN, J., SMITH C. P. A., TAFFOREAU, P. and LANDMAN, N. H. 2019. Data from: Enigmatic hook-like structures in cretaceous ammonites (Scaphitidae). Dryad Digital Repository. https://doi.org/10.5061/dryad.1bg1c1f.

KRUTA, I., LANDMAN, N. H., ROUGET, I, CECCA, F. and TAFFOREAU, P. 2013.The radula of the Late Cretaceous ammonite Rhaeboceras halli. Palaeontology, 55-6, 1-6.

KRUTA, I., LANDMAN, N. H. and TANABE, K. 2015. The radula in the Ammonoidea. 495515. In Klug et al. (eds). Ammonoid Paleobiology: from anatomy to ecology. Topics in Geobiology, 44, Springer. 934 pp.

LANDMAN, N. H., FRAAIJE, R. H. B., KLOFAK, S. M., LARSON, N. L., BISHOP, G. A. and KRUTA, I. 2014. Inquilinism of a baculite by a dynomenid crab from the Upper Cretaceous of South Dakota. American Museum Novitates, 3818, 1-16.

LANDMAN, N. H. and WAAGE, K. M. 1993. Scaphitid ammonites of the Upper Cretaceous (Maastrichtian) Fox Hills Formation in South Dakota and Wyoming. Bulletin of American Museum of Natural History, 215, 1-257. 
LANDMAN, N. H., KENNEDY, W. J., COBBAN, W. A., LARSON, N. L. and JORGENSEN, S. D. 2013. A new species of Hoploscaphites (Ammonoidea: Ancyloceratina) from cold methane seeps in the Upper Cretaceous of the U.S. Western Interior. American Museum Novitates, 3781, 1-39.

MEEK, F.B. and HAYDEN, F. V. 1856. Descriptions of new species of Gasteropoda and Cephalopoda from the Cretaceous formation of Nebraska Territory. Proceedings of the Academy of Natural Sciences of Philadelphia, 8, 70-72.

MESSENGER, J. B. and YOUNG, J. Z. 1999. The radular apparatus of cephalopods. Philosophical Transactions of the Royal Society B, 354, 161-182.

O’SHEA, S., JACKSON, G. D. and BOLSTAD, K. S. 2007. The nomenclatural status, ontogeny and morphology of Pholidoteuthis massyae (Pfeffer, 1912) new comb (Cephalopoda: Pholidoteuthidae). Reviews in Fish Biology and Fisheries, 17, 425-435.

ROELEVELD, M. A. 1988. Generic interrelationships within the Ommastrephidae (Cephalopoda). 277-314. In: Clarke, M. R. and Trueman E. R. (eds.). The Mollusca. Vol. 12. Paleontology and Neontology of Cephalopods. Academic Press, N.Y., 355pp.

TANABE, K., KRUTA, I. and LANDMAN N. H. 2015. Ammonoid buccal mass and jaw apparatus. 439-494. In Klug et al. (eds). Ammonoid Paleobiology: from anatomy to ecology. Topics in Geobiology, 44, Springer. 934 pp.

WITMER, L.M. 1995. The extant phylogenetic bracket and the importance of reconstructing sort tissues in fossils, 19-33. In Thomason J. J. (ed). Functional morphology in vertebrate paleontology. Cambridge: Cambridge University Press. 296 pp.

\section{Figure Captions}

Figure 1. A. Ammonite zonation of the U.S. Western Interior (modified from Cobban et al., 2006) showing the zones containing hook-like structures. B. Map showing localities at which hook-like structures occur. 1. Baculites reesidei-B.jenseni Zones, Bearpaw Shale, Garfield County, Montana. 2. Hoploscaphites nicolletii-H. nebrascensis Zones, Fox Hills Formation, Dewey, Ziebach, and Corson counties, South Dakota. 3. B. scotti-Didymoceras 
nebrascense Zones, Pierre Shale, Butte County, South Dakota. 4. B. compressusB. cuneatus Zones, Pierre Shale, Meade County, South Dakota. 5. B. scottiD. nebrascense Zones, Pierre Shale, Fall River County, South Dakota.

Figure 2. Overall views of Rhaeboceras halli with hooks. A-C AMNH 64405. D-E AMNH 66433. A, D. Photographs with the hooks exposed on the flank. The black arrow indicates the beginning of the phragmocone. The white arrow indicates the lower jaw. B, E. 3D rendering of the hooks with the body chamber in transparency. C, F. Sketch of the hooks in the body chamber. Hooks embedded in the matrix and revealed with X-rays are in dashed lines. The white arrows indicate the lower jaw, and the dashed lines the portion of the jaw embedded in the matrix. Scale bar $1 \mathrm{~cm}$.

Figure 3. Schematic drawing of the hook morphology and landmarks. A. View with the opening. B. Other side view. Scale bar $2 \mathrm{~mm}$.

Figure 4. SEM micrographs of the black layer comprising the hooks. A. Cross section of the hook showing the black material (brushite) underlined by white dashed lines and indicated by an arrow. The internal portion of the hooks forms a cavity infilled with sediment during the fossilization process. B. Surface of the black material. Scale bar $400 \mu \mathrm{m}$.

Figure 5. Hook diversity with outer and opening views represented. 3-D rendering VG Studio MAX 3.0. Scale bar $2 \mathrm{~mm}$.

Figure 6. PCA of the hooks with landmarks for all specimens.

Figure 7. Gaussian mixture analysis and shape of the center of gravity for each morphogroup.

Figure 8. A. Centroid size per group for all the specimens. B. Boxplot of the centroid size per group for AMNH 66350. 
Figure 9. Gaussian mixture analysis on the flipped hook dataset and shape of the center of gravity for each group.

Figure 10. Boxplots of the centroid sizes of hooks scattered by specimens and groups in relation with the shell whorl height $(\mathrm{mm})$. Specimen numbers are indicated next to each boxplot, the numbers of hooks are written in brackets. For AMNH 66350, 66433 and 66434 only parts of the body chamber are preserved, the estimates are based on more complete specimen of comparable size (e.g. AMNH 95898).

Table 1. Scaphitid species in which hook-like structures occur. * : attributed to this species by close association, the structures are not preserved in the body chamber. 